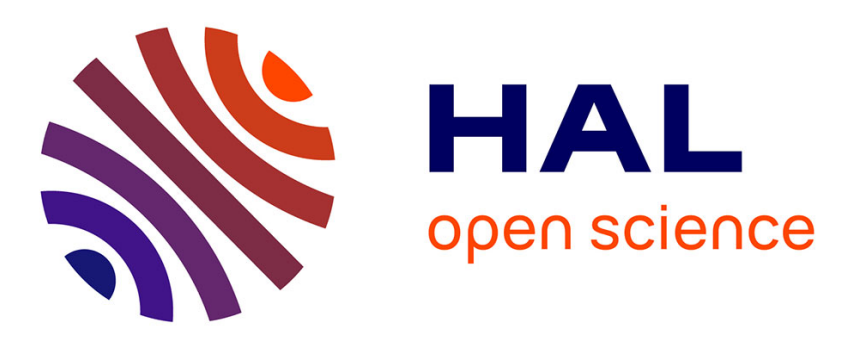

\title{
Hydrodeoxygenation and hydrogenolysis of biomass-based materials using FeNi catalysts and magnetic induction
}

Irene Mustieles Marin, Déborah de Masi, Francesco Fazzini, Lise-Marie Lacroix, Pier-Francesco Fazzini, Piet W N M van Leeuwen, Juan M Asensio, Bruno Chaudret

\section{To cite this version:}

Irene Mustieles Marin, Déborah de Masi, Francesco Fazzini, Lise-Marie Lacroix, Pier-Francesco Fazzini, et al.. Hydrodeoxygenation and hydrogenolysis of biomass-based materials using FeNi catalysts and magnetic induction. Green Chemistry, 2021, 23 (5), pp.2025-2036. 10.1039/D0GC03495A . hal-03210857

\section{HAL Id: hal-03210857 \\ https://hal.science/hal-03210857}

Submitted on 28 Apr 2021

HAL is a multi-disciplinary open access archive for the deposit and dissemination of scientific research documents, whether they are published or not. The documents may come from teaching and research institutions in France or abroad, or from public or private research centers.
L'archive ouverte pluridisciplinaire HAL, est destinée au dépôt et à la diffusion de documents scientifiques de niveau recherche, publiés ou non, émanant des établissements d'enseignement et de recherche français ou étrangers, des laboratoires publics ou privés. 


\title{
Hydrodeoxygenation and Hydrogenolysis of Biomass-Based Materials Using FeNi Catalysts and Magnetic Induction
}

\author{
Irene Mustieles Marin, Déborah De Masi, Lise-Marie Lacroix, Pier Francesco Fazzini, \\ Piet W. N. M. van Leeuwen, Juan M. Asensio and Bruno Chaudret* \\ LPCNO, Université de Toulouse, CNRS, INSA, UPS, 135 avenue de Rangueil, 31077 \\ Toulouse, France.
}

\begin{abstract}
:
Bimetallic $\mathrm{FeNi}_{3}$ nanoparticles (NPs) enriched with $\mathrm{Ni}\left(\mathrm{FeNi}_{3} @ \mathrm{Ni}\right.$ ) have been used to perform the hydrodeoxygenation reaction (HDO) and cleavage of lignocellulose-derived products in solution using magnetic induction. The application of a high frequency magnetic field induces high temperatures at the surface of the NPs that drive the catalytic reaction. The activation of the $\mathrm{C}-\mathrm{O}$ bond of several functional groups was studied. $\mathrm{FeNi}_{3} @ \mathrm{Ni}$ NPs, which act both as catalysts and magnetic heating agents, catalyzed the total conversion of furfural and 5-hydroxymethyl furfural into respectively 2-methylfuran and 2,5-dimethylfuran under mild conditions (12 mol\% catalyst, 3 bar $\mathrm{H}_{2}, 49 \mathrm{mT}$ ). The oligomerization of cyclopentanone, derived from furfural, was also achieved to yield $\mathrm{C}_{10}$ and $\mathrm{C}_{15}$ oligocyclopentyl products. Under the same conditions, diphenyl and benzyl phenyl ether, used as model molecules of polymeric lignin, were cleaved at $86 \%$ and $100 \%$ conversion respectively, to yield a mixture of hydrogenolysis and hydrogenated products. This is explained by the presence of $\mathrm{Ni}$ at the surface of the NP that favors the hydrogenation of the aromatic rings. The short reaction times and simplicity of the experimental set-up highlight the advantages of the application of magnetic heating for difficult transformations in solution, here the catalytic treatment of biomass-derived molecules.
\end{abstract}

\section{Introduction}

The transformation of biomass residues into valuable chemicals is a timely and important research topic to anticipate the fossil resources shortage and develop new ways to access valuable carbon- 
based molecules. For this purpose, numerous processes have been developed to hydrolyze biomass, reduce it and depolymerize natural polymers such as cellulose or lignin..$^{1-3}$ One important process is hydrodeoxygenation (HDO) which has been extensively studied during the past few years. ${ }^{4-6}$ For instance, furfural and 5-hydroxymethylfurfural (HMF), which are generated by the respective dehydration of $\mathrm{C}_{5}$ and $\mathrm{C}_{6}$ sugars in the acid hydrolysis of lignocellulose, yield 2-methylfuran (MF) and 2,5-dimethylfuran (DMF) as hydrodeoxygenation products, which are considered as promising biofuel candidates due to their high octane number and physicochemical properties. ${ }^{7-10}$ This transformation has been studied with noble $(\mathrm{Ru}, \mathrm{Pd})^{11-14}$ and non-noble $(\mathrm{Cu}, \mathrm{Co}, \mathrm{Ni})^{15-18}$ metal catalysts for which harsher conditions are required (temperatures up to $280{ }^{\circ} \mathrm{C}$ and pressures ranging from 10 to 50 bar). ${ }^{5}$ It has been observed that the use of bimetallic catalysts may enhance the selectivity towards the $\mathrm{HDO}$ product. This is the case of the $\mathrm{Ni} / \mathrm{SiO}_{2}$ catalyst reported by Sitthisa et al., for which the yield on MF increased from $1.4 \%$ (at $51 \%$ conversion) with only Ni as catalyst, to $39 \%$ (at $96 \%$ conversion) when a Ni-Fe alloy was used (5 wt\% Ni-2 wt\% Fe). ${ }^{19}$ Thus, this group $^{19,} 20$ as well as that of Lercher ${ }^{21}$ have reported that FeNi alloys are able to reduce the kinetic barrier for $\mathrm{C}-\mathrm{O}$ bond activation in HDO reactions. In addition, oligomerization of cyclopentanone, a product of furfural hydrogenation, ${ }^{22}$ can be of interest for the production of high-density biofuels with applications in the aviation field. ${ }^{23-25}$ As demonstrated by Wang et al., $\mathrm{C}_{15}$ and $\mathrm{C}_{20}$ hydrocarbons can be obtained by aldol condensation of this molecule..$^{23}$

Similarly, several studies have focused on the potential of lignin as the largest natural source of low-carbon aromatics. ${ }^{26}$ Lignin is constituted by methoxy-phenol units linked mostly by strong ether bonds. ${ }^{27}$ In this respect, di-aryl and alkyl-aryl ethers such as diphenyl ether (DPE) and benzyl phenyl ether (BPE) are commonly used as model substrates to investigate the catalytic cleavage of the polymer. These structures display the 4-0-5 and $\alpha-0-4$ linkage features, widely present in lignin ${ }^{28}$ with bond dissociation energies (BDE) ranging from 218 to $314 \mathrm{~kJ} \mathrm{~mol}^{-1}$ hence requiring harsh conditions to be cleaved. ${ }^{29}$ The catalytic hydrogenolysis of these model molecules has been widely studied in homogeneous and heterogeneous catalysis here again with nickel-based catalysts. Lercher et al. investigated the cleavage of alkyl-aryl and aryl-aryl ethers on silica-supported nickel NPs $(4-8 \mathrm{~nm})$ under mild conditions $\left(120^{\circ} \mathrm{C}, 6\right.$ bar of $\left.\mathrm{H}_{2}\right)$, yielding a mixture of aromatics and 
cycloalkanes. $^{30}$ In an initially homogeneous system, Hartwig et al. reported total conversion of aromatic ethers to the corresponding monomers. ${ }^{31}$

The practical difficulties linked to biomass transformation, especially the problems of heat and mass transfer, call for the search for new, less expensive and easy-to-implement catalytic systems. In this respect, the use of magnetically heated catalysts present inside the reaction mixtures could be advantageous in terms of heat diffusion. Ferromagnetic nanoparticles (NPs) can produce heat when exposed to an alternating magnetic field working at high frequency. This technique has been mostly applied in biology for cancer therapy: the so-called magnetic hyperthermia. ${ }^{32}$ More recently, magnetic heating has also been applied to activate catalytic reactions as it permits generating a rapid and localized rise of the temperature at the surface of the heating agents without the need to heat up the whole reactor. Several groups including ours, explored the magnetic activation of heterogeneous catalytic reactions in the gas phase such as the Fischer-Tropsch reaction, ${ }^{33},{ }^{34} \mathrm{CO}_{2}$ hydrogenation, ${ }^{35-39}$ methane reforming ${ }^{40-43}$ or alkane dehydrogenation. ${ }^{43}$ Magnetic heating has also been used in liquid phase reactions, but it was often limited to reactions taking place at moderate temperatures such as $\mathrm{C}-\mathrm{C}$ coupling, ${ }^{44}$ amide condensation, ${ }^{45}$ and more recently hydrogenation of furfural. ${ }^{46}$ In order to have access to higher temperatures, we investigated the design of hybrid materials in which the catalyst is in close contact with the heating agent, namely FeC NPs decorated with Ru NPs (FeC@Ru).47 In this way, we were able to reach local high temperatures, well-above the mean temperature of the bulk solution and to perform the HDO of platform molecules under much lower pressures ( 3 bar $\mathrm{H}_{2}$ ) and low catalyst loadings $\left(0.25-1\right.$ mol\% Ru). ${ }^{47}$ This experiment suffered however from two drawbacks: the use of a noble metal catalyst and the complex synthesis of the FeC@Ru nanoparticles. In order to prove the efficiency of the magnetic activation in solution, we turned to the FeNi system. Thus, $\mathrm{FeNi}_{3} \mathrm{NPs}$ which display low magnetocrystalline anisotropy, catalyze the $\mathrm{CO}_{2}$ hydrogenation at lower magnetic field than previously reported materials, e.g. $\mathrm{FeC}^{35}$ and FeCo NPs, ${ }^{43}$ thus improving the energy efficiency of the process. ${ }^{48}$ Furthermore, $\mathrm{FeNi}_{3}$ NPs are easily synthesized and can also be easily enriched with additional nickel leading to $\mathrm{FeNi}_{3} @ N i$ NPs. Finally they are good candidates for HDO and ether cleavage reactions as mentioned above. 
In this paper, we report the catalytic activity of $\mathrm{FeNi}_{3} @ \mathrm{Ni} \mathrm{NPs}$ in HDO in solution using magnetic heating. The cleavage of the $\mathrm{C}-\mathrm{O}$ bond was achieved for a range of substrates under mild conditions and a catalyst loading of $12 \mathrm{~mol} \%$. HDO, oligomerization and cleavage of biomass-derived products were performed at low $\mathrm{H}_{2}$ pressure (3 bar) in the absence of any noble metal. These reactions evidence the interest of magnetically activated catalysis which allows one to perform difficult reactions using a simple set-up and low pressure, while high temperatures only build up at the surface of the nano-catalysts.

\section{Experimental part}

$\mathrm{FeNi}_{3} @ \mathrm{Ni} \mathrm{NPs}$ were prepared following the procedure recently reported by De Masi et al. and is described in the supplementary information. ${ }^{48}$ These particles can be obtained by reduction of the organometallic precursors $\left\{\mathrm{Fe}\left[\mathrm{N}\left(\mathrm{SiMe}_{3}\right)_{2}\right]_{2}\right\}_{2}$ and $\mathrm{Ni}\left[{ }^{\mathrm{P} P N C}\left(\mathrm{CH}_{3}\right) \mathrm{N}^{i} \mathrm{Pr}\right]_{2}$, under $\mathrm{H}_{2}$ in the presence of palmitic acid. As prepared, the particles possess a Fe-Ni core with a Fe-rich surface. A second reaction step serves to enrich the surface with additional nickel, leading to FeNi $\mathrm{N}_{3} @ \mathrm{Ni}$ NPs.

The NPs have been characterized by X-ray Diffraction (XRD), Transmission Electron Microscopy (TEM), High Resolution Transmission Electron Microscopy (HR-TEM) and Scanning Transmission Microscopy-Energy Dispersive Analysis by X-Ray (STEM-EDX). The X-ray diffractograms only show the peaks of the $f c c$ structure corresponding to $\mathrm{FeNi}_{3}$ and/or Ni. After catalysis no significant changes in the peaks position and linewidth were observed (see Figure 1).

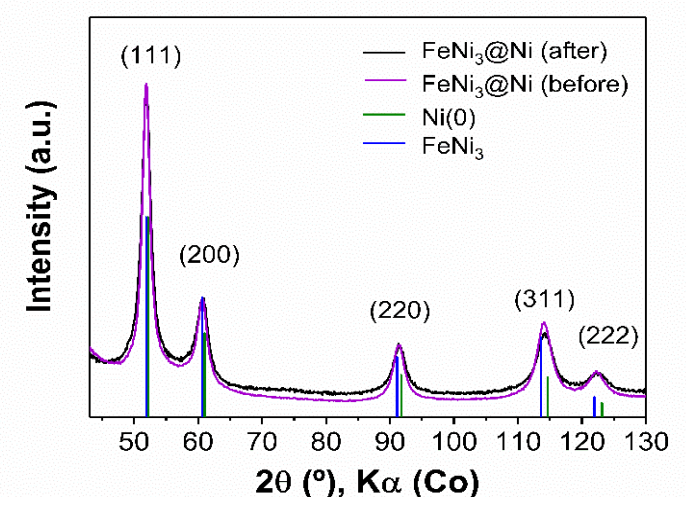

Figure 1. X-ray diffractograms of $\mathrm{FeNi}_{3} @ \mathrm{Ni}$ NPs before (purple line) and after (black line) hydrogenolysis of diphenyl ether. 
TEM analysis of the particles have also been performed before and after catalysis, namely furfural HDO, diphenyl ether hydrogenolysis and reaction with cyclopentanone. Representative examples of images obtained before and after reaction with cyclopentanone are shown on Figure 2. TEM analysis were performed on nanoparticles after 3 catalytic cycles. The particles display a mean size near $16 \mathrm{~nm}$ and no significant change in the size distribution is observed for TEM micrographs recorded after catalysis (see SI, Figure S1). However, as a general trend, a noticeable agglomeration of the NPs was observed after catalysis.

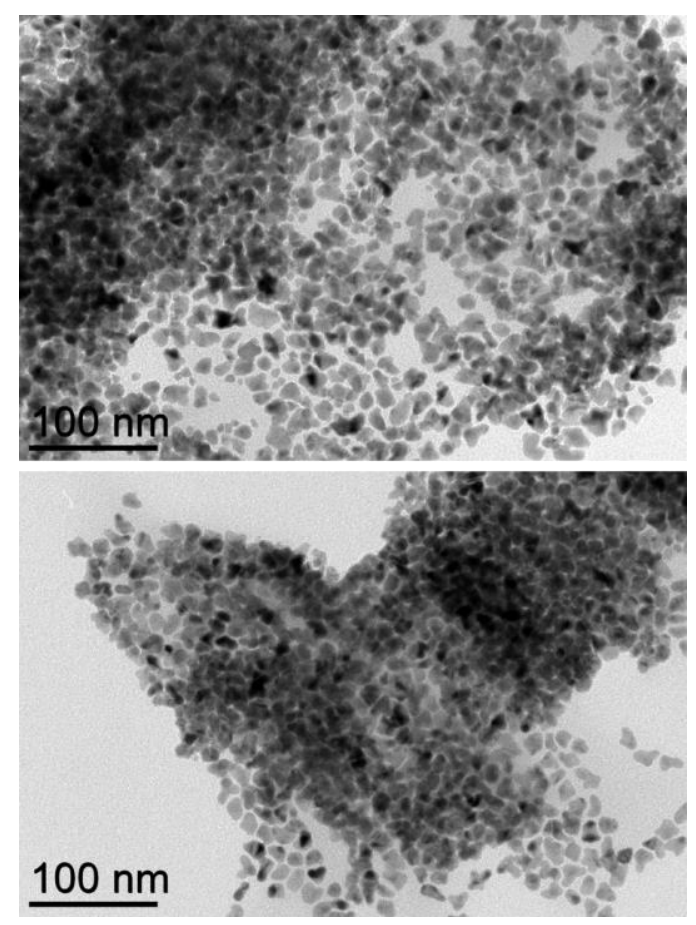

Figure 2. TEM images of $\mathrm{FeNi}_{3} @ N i$ NPs before (top) and after three catalytic runs with cyclopentanone (bottom).

HR-TEM studies evidence the $f c c$ structure of $\mathrm{FeNi}_{3}$ in agreement with the XRD results. STEM/EDX was used to check the presence of both $\mathrm{Ni}$ and $\mathrm{Fe}$ in the particles and to observe their local distribution. This technique clearly demonstrates the presence of both iron and nickel in the particles (see Figure 3). 

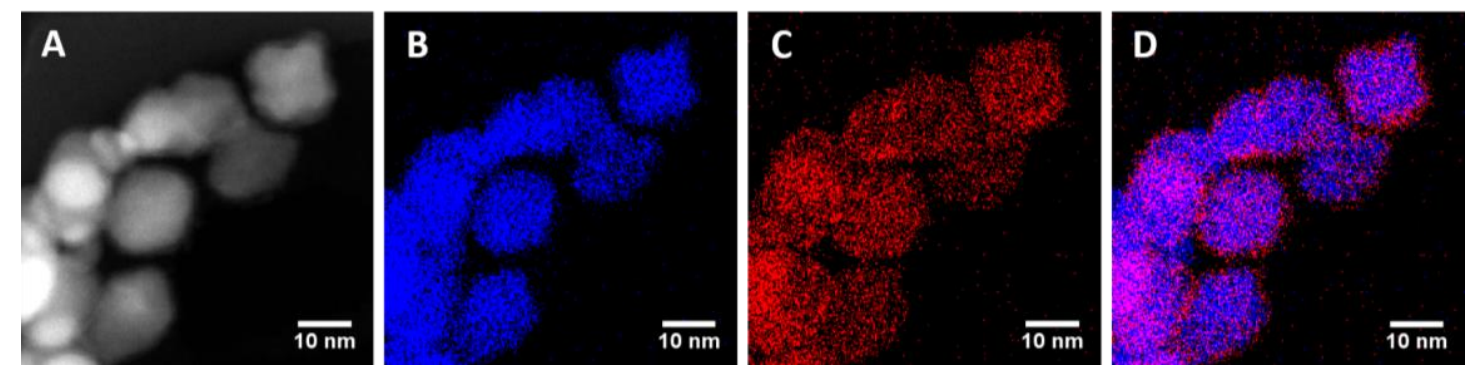

Figure 3. HR-TEM image (A) and STEM-EDX results obtained on FeNi 3 @i NPs and evidencing the presence of $\mathrm{Ni}(\mathrm{B}), \mathrm{Fe}(\mathrm{C})$ and Ni-Fe superposition (D).

Regarding the magnetic properties, these NPs are superparamagnetic at $300 \mathrm{~K}$ and display a magnetization at saturation value of $87 \mathrm{~A} \cdot \mathrm{m}^{2} \cdot \mathrm{kg}^{-1}$. The Specific Absorption Rate (SAR), a property related to the heating power of the NPs, measured at $93 \mathrm{kHz}$ and $47 \mathrm{mT}$, was $350 \mathrm{~W} \cdot \mathrm{g}^{-1}$ (see SI, Figure S2). A brief description of the magnetic properties is presented in the Supporting Information.

The catalytic reactions were performed using a $3 \mathrm{~cm}$ wide and $2 \mathrm{~cm}$ high coil working at $300 \mathrm{kHz}$. The magnetic field amplitude can be settled between 0 and $65 \mathrm{mT}$. A view of the set-up is presented on Figure S3. A typical catalytic procedure as well as an example of a GC-MS chromatogram is shown in the Supporting Information.

\section{Results}

\section{Hydrodeoxygenation of acetophenone}

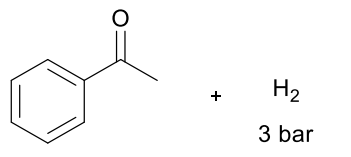

Recycling

1 st use

3rd use

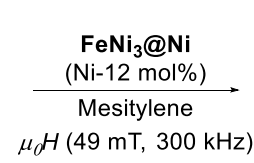
Conversion
$100 \%$
$82 \%$
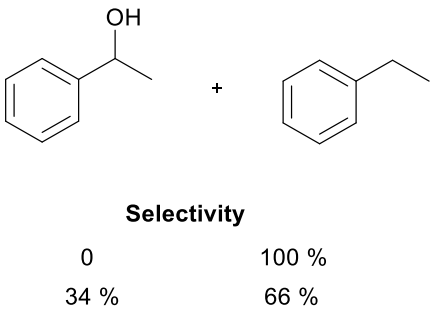

Scheme 1. Reaction pathway for acetophenone HDO and catalytic results obtained after three recycling cycles.

Preliminary studies for HDO were performed using acetophenone as a model substrate. Mesitylene was used as solvent because of its high boiling point (ca. $165^{\circ} \mathrm{C}$ ). Magnetic field amplitude of $49 \mathrm{mT}$ 
was chosen for the reaction since it maximizes the SAR of $\mathrm{FeNi}_{3} @ N i$ NPs (see Fig. S2). The HDO was performed using $12 \mathrm{~mol} \%$ of catalyst and 3 bar of $\mathrm{H}_{2}$. When the magnetic field was applied, the NPs reorganized to form chains along the magnetic field direction (see Fig. S3) as previously observed by our group with FeC@Ru NPs. ${ }^{47}$ In addition, solvent boiling could be observed in the vicinity of the NPs, while a temperature of $150-160{ }^{\circ} \mathrm{C}$ was determined on the Fisher-Porter bottle external walls using an IR camera.

After 3 hours, total conversion of acetophenone was achieved with a full selectivity for the expected HDO product, ethylbenzene. The recyclability of the NPs then was studied. After three cycles, the conversion decreased to $82 \%$ and the selectivity for ethylbenzene dropped to $66 \%$. TEM images evidenced the agglomeration of the NPs after reaction (see Figure 2). This important morphology change leads to a reduction of both the catalytically active surface and the heating power, since the agglomerated NPs can no longer self-organize to form chains.

\section{Hydrodeoxygenation of furfural}

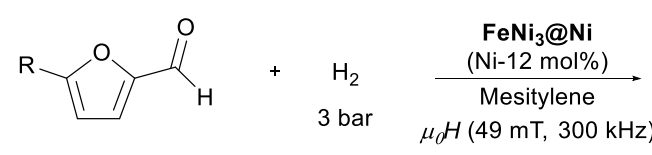

$\mathrm{FL}, \mathrm{R}=\mathrm{H}$ $\mathrm{HMF}, \mathrm{R}=\mathrm{CH}_{2} \mathrm{OH}$

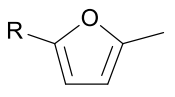

$\mathrm{MF}, \mathrm{R}=\mathrm{H}$ DMF, $\mathrm{R}=\mathrm{CH}_{3}$

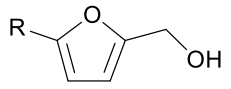

$\mathrm{FA}, \mathrm{R}=\mathrm{H}$ HMMF, $\mathrm{R}=\mathrm{CH}_{3}$

Scheme 2. Hydrodeoxygenation reaction of furfural and HMF. FL = furfural, HMF = 5-hydroxymethylfurfural, $\mathrm{MF}=$ 2-methylfuran, FA = furfuryl alcohol, DMF = 2,5-dimethylfuran, HMMF = 5-methyl-2-furfuryl alcohol.

The hydrodeoxygenation of furfural under magnetic heating was studied as a function of $\mathrm{H}_{2}$ pressure, magnetic field and catalyst loading in mesitylene. After 1 hour in the presence of 3 bar of $\mathrm{H}_{2}, 12 \mathrm{~mol} \%$ of catalyst and a magnetic field amplitude of $49 \mathrm{mT}$ (reference experiment, see Scheme 2), $64 \%$ of furfural was converted leading to a $51 \%$ yield of furfuryl alcohol (FA) and $13 \%$ of methylfuran (MF). As in the case of acetophenone, the pressure increase in the Fisher-Porter bottle was of only 0.2 bar during the reaction.

- Influence of the pressure (Table 1, entries 2 and 3): 
The reaction was performed for 1 hour at variable pressure while maintaining the catalyst loading (12 mol\%) and the magnetic field amplitude constant (49 mT). By increasing the $\mathrm{H}_{2}$ pressure from 1 to 5 bar, the furfural conversion varied from 42 to $74 \%$. Furfuryl alcohol and methylfuran were the only reaction products. Indeed, even at high pressure, no hydrogenation of the aromatic ring was observed. FA was the major product obtained independently of the pressure.

\begin{tabular}{|c|c|c|c|c|c|c|}
\hline \multirow{2}{*}{ Entry } & \multirow{2}{*}{$\begin{array}{l}\text { Pressure } \\
\text { (bar) }\end{array}$} & \multirow{2}{*}{$\begin{array}{l}\text { Catalyst } \\
\text { loading } \\
\text { (mol\%) }\end{array}$} & \multirow{2}{*}{$\begin{array}{c}\text { Magnetic field } \\
\text { (mT) }\end{array}$} & \multirow{2}{*}{$\begin{array}{c}\text { Conversion } \\
\text { (\%) }\end{array}$} & \multicolumn{2}{|c|}{ Yield (\%) } \\
\hline & & & & & FA & MF \\
\hline $\begin{array}{c}\text { 1(reference } \\
\text { reaction) }\end{array}$ & 3 & 12 & 49 & 64 & 51 & 13 \\
\hline 2 & 1 & 12 & 49 & 42 & 37 & 5 \\
\hline 3 & 5 & 12 & 49 & 74 & 61 & 13 \\
\hline 4 & 3 & 12 & 33 & 49 & 42 & 7 \\
\hline 5 & 3 & 12 & 60 & 60 & 50 & 10 \\
\hline 6 & 3 & 6 & 49 & 10 & 9 & 1 \\
\hline 7 & 3 & 24 & 49 & 79 & 57 & 22 \\
\hline 8 & 3 & 12 & $\begin{array}{c}{ }^{*} \text { Conventional } \\
\text { heating }\end{array}$ & 60 & 55 & 5 \\
\hline
\end{tabular}

Table 1. Conversion and partial yields obtained for the optimization of furfural HDO conditions. Conditions: 1 mmol of substrate, $5 \mathrm{~mL}$ of mesitylene, 1 hour of reaction. ${ }^{*}$ The temperature used was $180^{\circ} \mathrm{C}$.

- Influence of the magnetic field (Table 1, entries 4 and 5):

To determine the influence of the magnetic field on the catalytic process the reactions were carried out for 1 hour at $33 \mathrm{mT}, 49 \mathrm{mT}$ and $60 \mathrm{mT}$ magnetic field amplitudes. FA remained as the main product with similar selectivities in all the three cases. Regarding the conversion, it decreased from 64 to $49 \%$ when reducing the magnetic field from 49 to $33 \mathrm{mT}$. However, it barely changed when the reaction was conducted at $60 \mathrm{mT}(60 \%)$. This may be due to the fact that the $\mathrm{FeNi}_{3} @ \mathrm{Ni}$ NPs SAR value significantly increases between 33 and $49 \mathrm{mT}$ (190 vs $350 \mathrm{~W} \cdot \mathrm{g}^{-1}$ Fig. S2), but then saturates at high field. These results evidence the key importance played by the NPs heating power in the catalytic process. 
- Influence of the catalyst loading (Table 1, entries 6 and 7):

The influence of the catalyst loading was also investigated by using lower (6 mol\%) and higher (24 mol\%) amounts of catalyst compared to the $12 \%$ used in the reference conditions. A drastic increase of the furfural conversion from 10 to $64 \%$ was observed when the catalyst loading was doubled from 6 to $12 \mathrm{~mol} \%$. Increasing the catalyst loading up to 24 mol\% led to $79 \%$ conversion. The improvement is thus less drastic but a higher selectivity for MF was observed, which is explained by the increase of temperature due to a higher SAR caused by the formation of larger/longer chains. ${ }^{49,50}$

These studies show that $12 \mathrm{~mol} \%$ of catalyst loading, 3 bar of $\mathrm{H}_{2}$ and a magnetic field of $49 \mathrm{mT}$ are the best compromise between good conversion, mild conditions and catalytic loading, and therefore these were kept for further investigations.

- Reaction profile of furfural:

The HDO of furfural was further investigated at different reaction times under the optimized catalytic conditions. The reaction profile is shown on Figure 4.

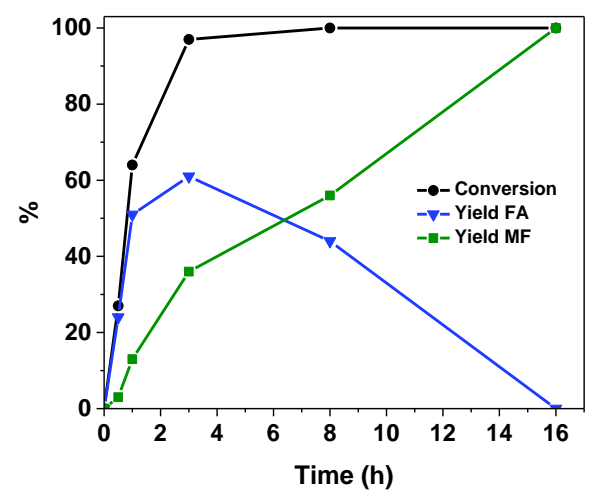

Figure 4. Furfural conversion and products yield as a function of the time. Conditions: 1 mmol substrate, 49 $\mathrm{mT}, 3$ bar $\mathrm{H}_{2}, 12 \mathrm{~mol} \%$ of catalyst, and $5 \mathrm{~mL}$ of mesitylene.

The conversion of furfural occurred very fast. After 3 hours, furfural was almost totally converted into FA and MF, with 61 and $36 \%$ yield, respectively. At short reaction times, the major product was FA, which was further converted to MF (see Table 2). Thus, total selectivity for the final product was obtained after 15 hours of reaction. The reaction is highly selective and no side- 
products resulting from ring-hydrogenation, ring-opening or decarbonylation processes were observed.

\begin{tabular}{ccccc}
\hline \multirow{2}{*}{ Entry } & Time (h) & Conversion & \multicolumn{2}{c}{ Yield (\%) } \\
\cline { 4 - 5 } & & $(\%)$ & FA & MF \\
\hline 1 & 0.5 & 28 & 24 & 4 \\
2 & 1 & 64 & 51 & 13 \\
3 & 3 & 97 & 61 & 36 \\
4 & 8 & 100 & 46 & 56 \\
5 & 16 & 100 & 0 & 100 \\
\hline
\end{tabular}

Table 2. Conversion and yields obtained in the HDO of furfural at different times. Conditions: $1 \mathrm{mmol}$ substrate, $49 \mathrm{mT}, 3$ bar $\mathrm{H}_{2}, 12 \mathrm{~mol} \%$ of catalyst, and $5 \mathrm{~mL}$ of mesitylene.

For the sake of comparison, the HDO of furfural was also studied with $\mathrm{FeNi}_{3} @ \mathrm{Ni}$ but using conventional heating (oil bath, $180^{\circ} \mathrm{C}$ ). After 3 hours of reaction in refluxing mesitylene under 3 bar of $\mathrm{H}_{2}$ at initial room temperature (4 bars at $180^{\circ} \mathrm{C}$ ), the conversion reached $60 \%$ but with a selectivity of only $8 \%$ for MF (see Table 1 ). The difference with magnetic heating will also be examined in the discussion section.

\section{Hydrodeoxygenation of hydroxymethylfurfural}

The HDO of HMF was monitored at different times using the same catalytic conditions as previously described (Figure 5).

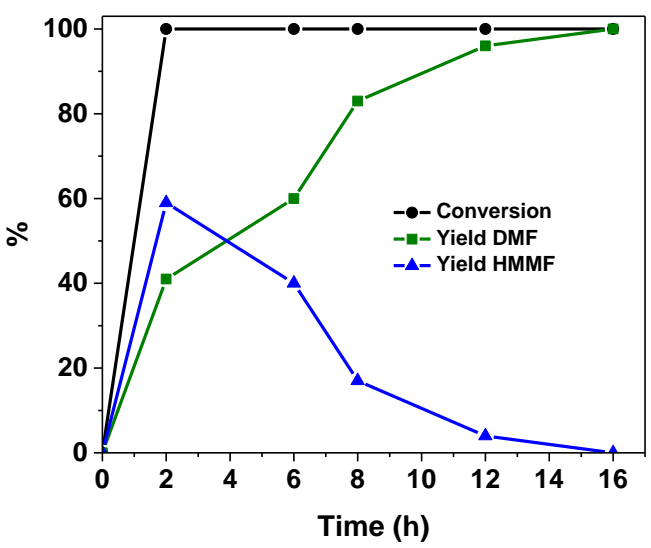


Figure 5. Hydroxymethylfurfural conversion and products yield as a function of the time. Conditions: $1 \mathrm{mmol}$ substrate, $49 \mathrm{mT}, 3$ bar $\mathrm{H}_{2}, 12 \mathrm{~mol} \%$ of catalyst, and $5 \mathrm{~mL}$ of mesitylene.

Similar to furfural, the conversion of HMF occurred very rapidly and was complete after $2 \mathrm{~h}$ leading to 5-methylfurfuryl alcohol (HMMF) and DMF with a $59 \%$ and $41 \%$ yield, respectively. At 8 hours, only $17 \%$ yield of HMMF was observed, and at 16 hours total conversion into the HDO product DMF was achieved (see Table 3).

\begin{tabular}{ccccc}
\hline \multirow{2}{*}{ Entry } & Time (h) & Conversion & \multicolumn{2}{c}{ Yield (\%) } \\
\cline { 4 - 5 } & & $(\%)$ & HMMF & DMF \\
\hline 1 & 2 & 100 & 59 & 41 \\
2 & 6 & 100 & 40 & 60 \\
3 & 8 & 100 & 17 & 83 \\
4 & 12 & 100 & 4 & 96 \\
5 & 16 & 100 & 0 & 100 \\
\hline
\end{tabular}

Table 3. Conversion and yields in the HDO of HMF at different times. Conditions: 1 mmol substrate, $49 \mathrm{mT}, 3$ bar $\mathrm{H}_{2}, 12 \mathrm{~mol} \%$ of catalyst, and $5 \mathrm{~mL}$ of mesitylene.

\section{Oligomerization of cyclopentanone}

Cyclopentanone oligomerization may lead to the formation of polycycloalkanes, which are promising molecules for fuel applications due to their high densities. ${ }^{23,}{ }^{24}$ The proposed mechanism involves aldol condensation followed by HDO. We investigated the performance of our catalytic system in this reaction in order to get further insight into the reactivity of $\mathrm{FeNi}_{3} \mathrm{NPs}$ towards the activation of $\mathrm{C}-\mathrm{O}$ bonds.

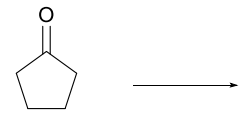

Conversion

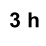

$8 \mathrm{~h}$

$16 \mathrm{~h}$

$80 \%$

$100 \%$

$100 \%$

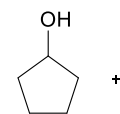

A

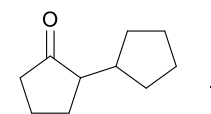

B

0

7

0

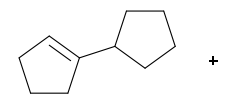

c

0

8

0

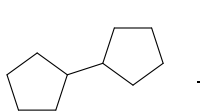

D

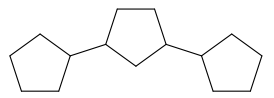

E

0

6

28

Figure 6. Oligomerization of cyclopentanone and product selectivities at 3, 8 and 16 hours. Conditions: $1 \mathrm{mmol}$ substrate, $49 \mathrm{mT}, 3$ bar $\mathrm{H}_{2}, 12 \mathrm{~mol} \%$ of catalyst, and $5 \mathrm{~mL}$ of mesitylene. 
After $3 \mathrm{~h}$ under standard conditions, $80 \%$ of the cyclopentanone was converted into cyclopentanol (see Figure 6). Total conversion was achieved after $8 \mathrm{~h}$ to yield a mixture of dimeric and trimeric products, while no cyclopentanol was observed. Cyclopentyl cyclopentane was the main product, $79 \%$, along with small amounts of dimers 2-cyclopentyl cyclopentanone (7 \%), 1-cyclopentyl cyclopentene (8\%), and the trimer 1,3-dicyclopentylcyclopentane $(6 \%)$. When the reaction was run for $16 \mathrm{~h}$, all the unsaturated dimers ( $\mathrm{B}$ and $\mathrm{C}$ ) were consumed and the final mixture was composed of $72 \%$ of cyclopentylcyclopentane and $28 \%$ of 1,3-dicyclopentylcyclopentane. The presence of cyclopentanol as the first reaction product is in contradiction with the proposed aldolisation mechanism. It is therefore more likely that the first step proceeds through cyclopentanol dehydration leading to a reactive cyclopentene.

\section{Cleavage of diphenyl ether and benzyl phenyl ether}

The cleavage of benzyl phenyl ether and diphenyl ether, two of the most common lignin model molecules, was investigated using the optimized conditions and $\mathrm{FeNi}_{3} @ \mathrm{Ni}$ NPs as catalyst. In this case decane was the solvent of choice for analytical reasons, as it displays a high boiling point (174 $\left.{ }^{\circ} \mathrm{C}\right)$. Figure 7 shows the conversion of diphenyl ether and the product distribution at 1, 2, 5, 8 and 15 hours. After this time no further evolution of the reaction was observed.

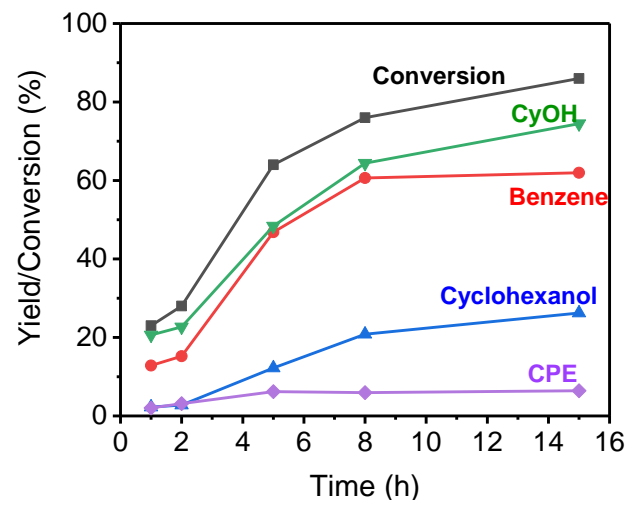

Figure 7. Conversion and products yield of DPE cleavage as a function of the time. Conditions: $1 \mathrm{mmol}$ substrate, $12 \mathrm{~mol} \%$ catalyst, 3 bar $\mathrm{H}_{2}, 49 \mathrm{mT}$, and $5 \mathrm{~mL}$ of decane. $\mathrm{CyOH}=$ cyclohexanol, $\mathrm{CPE}=$ cyclohexyl phenyl ether.

The conversion of DPE is slower than that of the furfural derivatives. At $15 \mathrm{~h} 86 \%$ conversion was achieved. The main products were cyclohexanol and benzene, indicating the direct hydrogenolysis 
of the aromatic $\mathrm{C}-\mathrm{O}$ bond (see Table 4). No phenol was observed at any time, suggesting that it is rapidly hydrogenated into cyclohexanol (see Scheme 3). Cyclohexane was also formed in minor amounts during the reaction as a result of the slow hydrogenation of benzene. Its yield increased with time and reached $26 \%$ at the end of the reaction. Small amounts of cyclohexyl phenyl ether (CPE) were also observed resulting from the partial hydrogenation of diphenyl ether. ${ }^{30,51}$ The yield of CPE reached a maximum of $6 \%$ after 5 hours and did not experience further variation.

For the sake of the interpretation, the reactivity of phenol and cyclohexyl phenyl ether were investigated in two control experiments under the standard conditions using $1 \mathrm{mmol}$ of phenol or CPE instead of DPE. After 5 hours of reaction, all the phenol was converted to cyclohexanol, while CPE did not react at all.

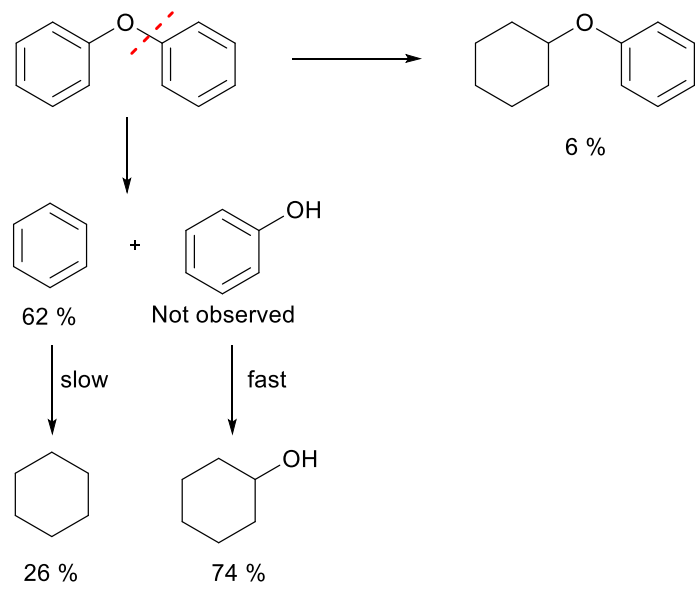

Scheme 3. Proposed reaction pathway for the cleavage of diphenyl ether and yields obtained at $15 \mathrm{~h}$ (86\% conversion).

\begin{tabular}{ccccccc}
\hline \multirow{2}{*}{ Entry } & Time & Conversion & \multicolumn{5}{c}{ Yield (\%) } \\
\cline { 4 - 7 } & $(\mathrm{h})$ & $(\%)$ & Benzene & CyOH & Cy & CPE \\
\hline 1 & 1 & 23 & 13 & 21 & 2 & 2 \\
2 & 2 & 29 & 15 & 23 & 3 & 3 \\
3 & 5 & 64 & 47 & 48 & 12 & 6 \\
4 & 8 & 76 & 61 & 64 & 21 & 6 \\
5 & 15 & 86 & 62 & 74 & 26 & 6 \\
\hline
\end{tabular}


Table 4. Conversion and yields obtained for the cleavage of DPE. Conditions: $1 \mathrm{mmol}$ substrate, $12 \mathrm{~mol} \%$ catalyst, 3 bar $\mathrm{H}_{2}, 49 \mathrm{mT}$, and $5 \mathrm{~mL}$ of decane. $\mathrm{CyOH}=$ cyclohexanol, $\mathrm{Cy}=$ cyclohexane, $\mathrm{CPE}=$ cyclohexyl phenyl ether.
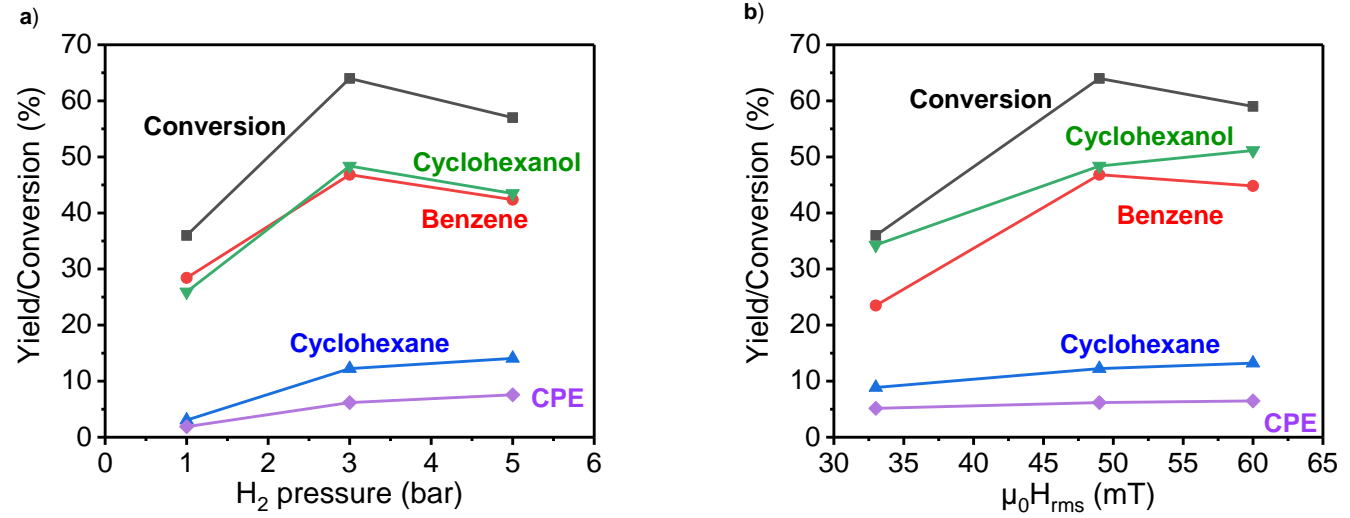

Figure 8. Conversion and yields obtained for the cleavage of DPE a) as a function of the pressure; and b) as a function of the magnetic field amplitude. Conditions: $1 \mathrm{mmol}$ of substrate, $12 \mathrm{~mol} \%$ of catalyst, 5 hours of reaction, $5 \mathrm{~mL}$ of decane, $49 \mathrm{mT}$ for a), and 3 bar $\mathrm{H}_{2}$ for $\mathrm{b}$ ).

The effect of hydrogen pressure and magnetic field amplitude were investigated in the cleavage of DPE after 5 hours of reaction. The results are shown in Table 5 and Figure 8. When the $\mathrm{H}_{2}$ pressure was increased from 1 to 3 bar, the conversion notably increased from 36 to $64 \%$. However, when further increasing the $\mathrm{H}_{2}$ pressure to 5 bar, a small decrease of the conversion from 64 to $55 \%$ was observed. Regarding the product distribution, a larger amount of the hydrogenated products cyclohexane and cyclohexyl phenyl ether was observed as a result of the higher hydrogen pressures, but benzene and cyclohexanol still remained as the main products. The change in the magnetic field amplitude, usually translated into a change of the catalyst surface temperature, did not have an influence on the product distribution. When increasing the field from 33 to $49 \mathrm{mT}$, the conversion increased from 36 to $64 \%$, but then slightly decreased to $59 \%$ at $60 \mathrm{mT}$. A similar effect was observed when using furfural as substrate and this is explained by the difference on the SAR measured at 33 and $49 \mathrm{mT}$. The small decrease observed at $60 \mathrm{mT}$ might be caused by the sintering of the NPs due to the high magnetic field amplitude applied.

\begin{tabular}{|c|c|c|c|c|c|c|c|}
\hline \multirow{2}{*}{ Entry } & \multirow{2}{*}{$\begin{array}{c}\mathrm{H}_{2} \\
\text { pressure } \\
\text { (bar) }\end{array}$} & \multirow{2}{*}{$\begin{array}{l}\mu_{0} \mathrm{H}_{\mathrm{rms}} \\
(\mathrm{mT})\end{array}$} & \multirow{2}{*}{$\begin{array}{l}\text { Conversion } \\
\qquad(\%)\end{array}$} & \multicolumn{4}{|c|}{ Yield (\%) } \\
\hline & & & & Benzene & Cyclohexanol & Cyclohexane & CPE \\
\hline 1 & 1 & 49 & 36 & 28 & 26 & 3 & 2 \\
\hline 2 & 3 & 49 & 64 & 47 & 48 & 12 & 6 \\
\hline
\end{tabular}




\begin{tabular}{cccccccc}
3 & 5 & 49 & 55 & 42 & 43 & 14 & 8 \\
\hline 4 & 3 & 33 & 36 & 23 & 34 & 9 & 5 \\
5 & 3 & 49 & 64 & 47 & 48 & 12 & 6 \\
6 & 3 & 60 & 59 & 45 & 51 & 13 & 3 \\
\hline 7 & 3 & *Conventional & 18 & 13 & 13 & 2 & \\
\hline
\end{tabular}

Table 5. Conversion and product selectivities obtained for the cleavage of DPE at different pressures and magnetic field amplitude. Conditions: $1 \mathrm{mmol}$ of substrate, $12 \mathrm{~mol} \%$ of catalyst, 5 hours of reaction and $5 \mathrm{~mL}$ of decane. ${ }^{*}$ The temperature used was $170^{\circ} \mathrm{C}$.

The activity of $\mathrm{FeNi}_{3} @ \mathrm{Ni}$ was also studied using conventional heating (oil bath, $170{ }^{\circ} \mathrm{C}$ ) instead of magnetic heating. The conversion only reached $18 \%$ at $5 \mathrm{~h}$ and the main products were benzene and cyclohexanol (see Table 5). As in previous experiments, no phenol was detected.

The cleavage of benzyl phenyl ether was investigated using magnetic heating under the optimized conditions. The reaction is faster than that of DPE and all the substrate was consumed after 5 hours (see Figure 9 and Table 6).

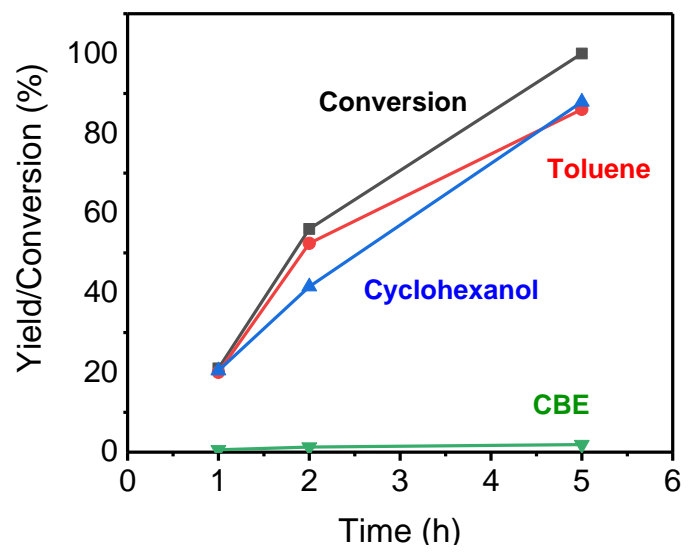

Figure 9. Conversion and product yields of BPE cleavage as a function of the time. Conditions: $1 \mathrm{mmol}$ substrate, $12 \mathrm{~mol} \%$ catalyst, 3 bar $\mathrm{H}_{2}, 49 \mathrm{mT}, 5 \mathrm{~mL}$ of decane.

From the beginning of the reaction the main products were toluene and cyclohexanol, in proportions which remained mostly constant (about $50 \%$ ) during the reaction. This indicates that the cleavage proceeds in this case via direct hydrogenolysis of the benzylic $\mathrm{PhCH}_{2}-\mathrm{O}$ bond. As observed with DPE, no phenol was detected in the reaction mixture due to its fast hydrogenation 
into cyclohexanol (see Scheme 4). Traces of a high-weight product were detected during the course of the reaction, identified as cyclohexyl benzyl ether (CBE), which is formed by partial hydrogenation of BPE. As occurred with $\mathrm{CPE}$, this product is present from the beginning of the reaction but does not evolve with time.

\begin{tabular}{cccccc}
\hline \multirow{2}{*}{ Entry } & Time (h) & $\begin{array}{c}\text { Conversion } \\
(\%)\end{array}$ & \multicolumn{3}{c}{ Yield (\%) } \\
\cline { 4 - 6 } & & & Toluene & CyOH & CBE \\
\hline 1 & 1 & 21 & 20 & 20 & 1 \\
2 & 2 & 56 & 52 & 42 & 1 \\
3 & 5 & 100 & 86 & 88 & 2 \\
\hline $4^{*}$ & 5 & 94 & 64 & 61 & 1 \\
\hline
\end{tabular}

Table 6. Conversion and yields obtained for the cleavage of BPE. Conditions: $1 \mathrm{mmol}$ substrate, $12 \mathrm{~mol} \%$ catalyst, 3 bar $\mathrm{H}_{2}, 49 \mathrm{mT}$, and $5 \mathrm{~mL}$ of decane.*Using conventional heating, the temperature used was $170{ }^{\circ} \mathrm{C}$.

At the end of the reaction the yields of toluene and cyclohexanol were close to $90 \%$, while the yield of the side-product cyclohexyl benzyl ether was only $2 \%$. No methylcyclohexane was observed as a result of toluene hydrogenation. Nevertheless, some traces of benzene were detected at $5 \mathrm{~h}$ of reaction, likely as the result of phenol hydrogenolysis.

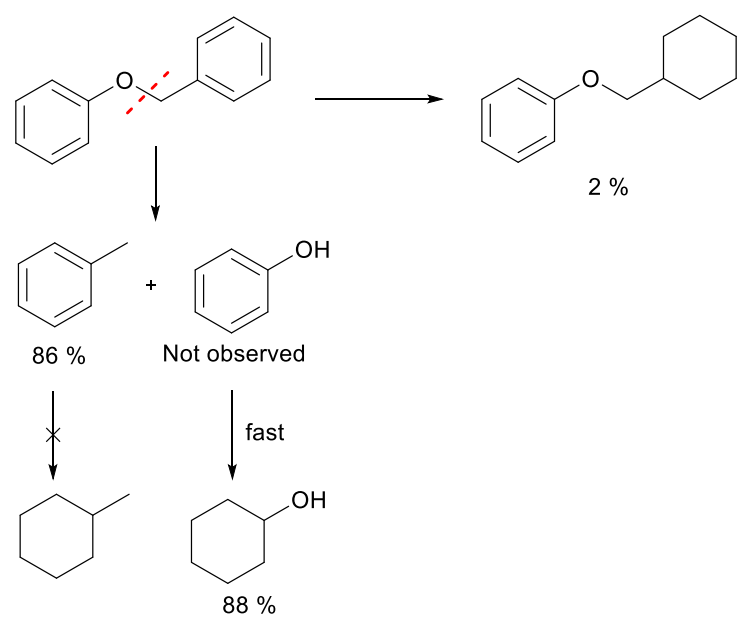

Scheme 4. Proposed reaction pathway for the cleavage of benzyl phenyl ether and yields obtained at $5 \mathrm{~h}$ (total conversion).

Using conventional heating, $\mathrm{FeNi}_{3} @ N i$ NPs converted 94 \% of the substrate (see Table 6). The main products were toluene and cyclohexanol with yields of 76 and $61 \%$ respectively. Cyclohexyl benzyl ether could only be detected at low concentrations. 


\section{Recyclability of the catalyst}

The recyclability of the NPs was studied for three of the substrates herein studied, namely furfural, cyclopentanone and diphenyl ether. Three reactions of 3 hours each were performed using the same batch of catalyst. Once the reaction was completed, the NPs were decanted with a magnet and the solution was removed and the reaction charged again with a new substrate and internal standard under inert atmosphere. Even though the NPs were decanted and easily separated from the solution, some NPs were dissolved during the reaction and some of them are also lost during solution removal, so catalyst charges are not comparable during recycling experiments. At the end of the three reactions (for all the three substrates), only $4 \mathrm{mg}$ of the 10 initial mg could be isolated.

Furfural:

\begin{tabular}{ccccc}
\hline \multirow{2}{*}{ Entry } & Time (h) & Conversion & \multicolumn{2}{c}{ Yield (\%) } \\
\cline { 4 - 5 } & & $(\%)$ & FA & MF \\
\hline 1 & 3 & 79.0 & 63 & 16 \\
2 & 3 & 85.0 & 20 & 65 \\
3 & 3 & 84.8 & 18 & 67 \\
\hline
\end{tabular}

Table 7. Conversion and yields obtained in the HDO of furfural at different times. Conditions: $1 \mathrm{mmol}$ substrate, $49 \mathrm{mT}, 3$ bar $\mathrm{H}_{2}$, initial $12 \mathrm{~mol} \%$ of catalyst, 3 hours of reaction and $5 \mathrm{~mL}$ of mesitylene.

We reported $97 \%$ conversion of furfural with 61\% furfuryl alcohol and 36\% of MF. In this precise experiment, the initial conversion is lower (see Table 7). However, after 2 recycles the conversion increases slightly and the selectivity towards MF increases spectacularly. Taking into account that we have less and less NPs in the Fisher-Porter bottle, these results show that the performance of our catalyst increases upon recycling.

Cyclopentanone:

\begin{tabular}{cccc}
\hline \multirow{2}{*}{ Entry } & Time (h) & Conversion & Selectivity (\%) \\
\cline { 3 - 3 } & & $(\%)$ & Cyclopentanol \\
\hline
\end{tabular}




\begin{tabular}{llll}
\hline 1 & 3 & 83.0 & 100 \\
2 & 3 & 85.8 & 100 \\
3 & 3 & 86.5 & 100 \\
\hline
\end{tabular}

Table 8. Conversion and selectivity obtained for the oligomerization of cyclopentanone in the recyclability tests. Conditions: $1 \mathrm{mmol}$ substrate, initial $12 \mathrm{~mol} \%$ catalyst, 3 bar $\mathrm{H}_{2}, 49 \mathrm{mT}$, 3 hours of reaction and $5 \mathrm{~mL}$ of mesitylene.

The conversion is similar to what has been observed with other batches of NPs and the selectivity is the same (see Table 8). Both conversion and selectivity are maintained after recycling.

Diphenyl ether:

\begin{tabular}{ccccccc}
\hline \multirow{2}{*}{ Entry } & Time & Conversion & \multicolumn{5}{c}{ Yield (\%) } \\
\cline { 4 - 7 } & $(\mathrm{h})$ & $(\%)$ & Benzene & CyOH & Cy & CPE \\
\hline 1 & 3 & 49 & 42 & 42 & 10 & 3 \\
2 & 3 & 26 & 24 & 15 & 9 & 1 \\
3 & 3 & 17 & 16 & 13 & 5 & 0 \\
\hline
\end{tabular}

Table 9. Conversion and yields obtained for the cleavage of DPE in the recyclability tests. Conditions: $1 \mathrm{mmol}$ substrate, initial $12 \mathrm{~mol} \%$ catalyst, 3 bar $\mathrm{H}_{2}, 49 \mathrm{mT}, 3$ hours of reaction and $5 \mathrm{~mL}$ of decane. $\mathrm{CyOH}=$ cyclohexanol, $\mathrm{Cy}=$ cyclohexane $\mathrm{CPE}=$ cyclohexyl phenyl ether.

The conversion obtained at the first reaction is coherent with other batches, as is the selectivity (see Table 9). After reusing the NPs, the conversion initially decreases but the selectivity is maintained.

These experiments are surprising since recycling improves the catalysis in the case of furfural, remains stable in the case of cyclopentanone and leads to a decrease of the conversion in the case of diphenyl ether. 


\section{Discussion}

Overall, $\mathrm{FeNi}_{3} @ \mathrm{Ni}$ NPs have been shown to be very active in the magnetically-induced HDO catalysis in solution. Reactions normally carried out at high temperature and pressure can be achieved in apparent mild conditions. In fact, these transformations are made possible by an overheating of the surface of the nano-catalyst which leads to local harsh conditions involving temperatures well above the boiling point of the solvent and possible pressure build up. Notwithstanding these harsh conditions produced at the nano-scale, only a slight overpressure in the reactor is produced and the reactions are completed despite the relatively low pressure ( 3 bar). A strong temperature gradient must be present to dissipate the heat produced by the nanoparticles.

In this respect, furfural and HMF can be selectively converted into their respective HDO products under 3 bar of $\mathrm{H}_{2}$ and using low loadings of catalyst. Furthermore, the Ni-decorated $\mathrm{FeNi}_{3} \mathrm{NPs}$ turned out to be more selective than other FeNi alloys previously reported, for which decarbonylated side-products were also produced during the reaction. ${ }^{19}$ Resasco et al. demonstrated that an $\eta^{2}(C-0)$ adsorption of the carbonyl group into the FeNi alloy catalyst surface was responsible for the selectivity towards MF. ${ }^{19}$ This coordination is favored by the presence of oxophilic Fe sites in the FeNi catalyst which weaken the coordinated C-O bonds. The absence of decarbonylated products in the HDO of furfural and HMF may be indicative of a greater stabilization of the $\eta^{2}(\mathrm{C}-\mathrm{O})$ intermediate by the $\mathrm{FeNi}_{3} @ \mathrm{Ni} \mathrm{NPs}$ which, thanks to the high temperatures reached by magnetic induction, promotes the $\mathrm{C}-\mathrm{O}$ cleavage over $\mathrm{C}-\mathrm{C}$ cleavage. In addition, no ring hydrogenation products were detected in any case, not even when the pressure was increased to 5 bar (Table 1, entry 3). It has previously been observed in the literature for conventional heating reactions that upon increasing hydrogen pressure the catalyst surface is saturated with hydrogen species, which hinders substrate coordination and thus decreases conversion..$^{30,51}$ The pressures used here are fairly low, therefore the conversion keeps on increasing with the $\mathrm{H}_{2}$ pressure, presumably because the NP surface is not saturated in hydrogen species.

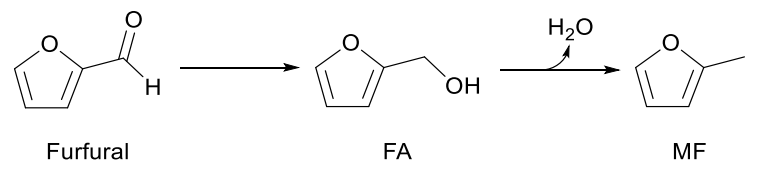


Scheme 5. Reaction pathway for furfural HDO.

The reaction profile of furfural conversion evidences the presence of the alcohol as intermediate and demonstrates that the reaction occurs in two steps (see Scheme 5). C-O bond cleavage, which possesses a higher activation energy, is slower than hydrogenation.

The conversion of HMF occurs faster than that of furfural, probably thanks to a better interaction with the catalyst surface favored by the additional hydroxyl group. At short reaction times HMMF was the main product followed by DMF while bis(hydroxymethyl)furan (BHMF) was not observed (see Scheme 6). The absence of the bis(hydroxymethyl) intermediate (BHMF) differs from the observations by the teams of Wang ${ }^{52,53}$ and Hoyos, ${ }^{54}$ who reported the formation of BHMF as intermediate of HMF to HMMF at low temperature at the beginning of the reaction when employing Ni-based catalysts. The absence of BHMF does not allow us to determine the reaction mechanism, which can occur through hydrogenation/hydrogenolysis of the carbonyl group with BHMF as intermediate, or hydrogenolysis of the hydroxyl group followed by hydrogenation of the aldehyde, which, in turn, would afford 5-methylfurfural as reaction intermediate. The conditions employed here in the transformation of both furfural and HMF appear notably milder than those generally reported in the literature. ${ }^{5} \mathrm{FeNi}_{3} @ \mathrm{Ni} \mathrm{NPs}$, acting both as catalyst and magnetic heating agent, may allow the HDO reaction to occur selectively at low pressures.

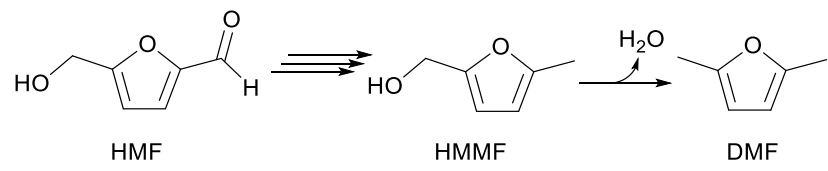

Scheme 6. Reaction pathway for hydroxymethylfurfural HDO.

This was demonstrated by comparing conventional heating (oil bath) and magnetically induced catalysis of furfural. After 3 hours of reaction at $180{ }^{\circ} \mathrm{C}$ and 3 bar of $\mathrm{H}_{2}$ pressure the conversion reached $60 \%$ with a selectivity of only $8 \%$ for the MF, while the conversion reached $97 \%$ with a $37 \%$ selectivity for MF when the reaction was magnetically heated (49 $\mathrm{mT})$ under the same reaction conditions (see Table 1). This is a good indication of the presence of local temperatures above the boiling point of the solvent in the case of the magnetic heating. In addition, higher overpressure (1 bar) was observed when conventional heating was used. In the presence of the magnetic coil, only a small increase of the pressure of 0.1-0.2 bar over the initial 3 bar was 
observed. The results obtained for these two reactions are similar to those reported previously for FeC@Ru NPs, ${ }^{47}$ but here they were obtained at lower magnetic field and hence lower energy consumption.

$\mathrm{FeNi}_{3} @ \mathrm{Ni}$ NPs were also demonstrated to be active in reactions not previously tested in magnetically activated catalysis such as the deoxygenating oligomerization of cyclopentanone, which was totally converted after 8 hours with a high selectivity for the $\mathrm{C}_{10}$ and $\mathrm{C}_{15}$ products after $16 \mathrm{~h}$. The synthesis of $\mathrm{C}_{10}$ and $\mathrm{C}_{20}$ polycycloalkanes obtained by condensation of cyclopentanone has been investigated by Zhang and co-workers under solvent-free conditions and in the presence of hydrogen. ${ }^{23,}{ }^{24}$ However, in that case, the presence of a base as well as a high $\mathrm{H}_{2}$ pressure (60 bars) was necessary. Here, total conversion of cyclopentanone to $\mathrm{C}_{10}$ and $\mathrm{C}_{15}$ olligocycloalkanes was obtained in a one-pot one-step synthesis without the presence of any base. Furthermore, the magnetic heating approach permits this oligomerization to take place at only 3 bar of $\mathrm{H}_{2}$ pressure, rendering the process much more accessible.

Magnetically induced catalysis was further proven to be effective in the cleavage of aryl-aryl and aryl-alkyl ethers, even though no total conversion was obtained in the case of DPE. A maximum conversion of $86 \%$ was obtained at $15 \mathrm{~h}$ for the latter, while BPE was totally converted at $5 \mathrm{~h}$. This difference is due to the lower bond dissociation energy of the C-O bond in the BPE $\left(218 \mathrm{KJ} \mathrm{mol}^{-1} \mathrm{vs}\right.$ $314 \mathrm{KJ} \mathrm{mol}^{-1}$ for DPE). ${ }^{29}$ In the case of DPE, the cleavage occurs via direct hydrogenolysis of the aryl C-O bond, while in BPE the aliphatic $\mathrm{PhCH}_{2}-\mathrm{O}$ bond is hydrogenolyzed (see Schemes 3 and 4). The phenol generated in the cleavage is directly hydrogenated into cyclohexanol and was not observed at any time of the reaction. This was confirmed by an independent experiment in which phenol was completely hydrogenated into cyclohexanol after $5 \mathrm{~h}$ using the same reaction conditions. On the other hand, benzene (in the case of diphenyl ether) was hydrogenated at lower rates, and toluene (in the case of benzyl phenyl ether) was not hydrogenated at all. Hartwig et al. demonstrated that the use of an in situ-generated Ni catalyst in the presence of a base increases the selectivity for the aromatic products in the cleavage of benzyl phenyl ether. ${ }^{31}$ In our case, the introduction of Fe likely increases the oxophilicity of the catalyst which favors the adsorption of phenol species facilitating the reduction of the aromatic ring. The small amounts of cyclohexane detected compared to cyclohexanol evidence the fact that the hydrogenation of the oxygenated product is preferred over 
the hydrogenation of benzene, due to the stronger interaction of the oxygen-containing molecule with the catalyst surface. The partial hydrogenated products, CPE and CBE, were present at low concentrations during all the reaction lifetime. Initially considered as a reaction intermediate in the C-O bond cleavage, the reactivity of CPE was investigated in a different experiment under the same reaction conditions. No conversion of CPE was observed after 5 hours of reaction indicating that CPE is not an intermediate but a side-product. This was also reported by Lercher et al. who observed that the rate of C-O bond cleavage of partially hydrogenated aryl ethers over a Ni-based catalyst turns out to be very low and therefore, other cleavage routes prevail. ${ }^{19}$ As the reaction evolves, other substrates such as phenol can cover the catalyst surface impeding the partial hydrogenation of the aryl ether. The conversion of DPE stopped after 15 hours of reaction perhaps as a result of sintering of the catalyst.

The comparison with conventional heating was studied for both substrates at short reaction times $(5 \mathrm{~h})$ at $170{ }^{\circ} \mathrm{C}$. Taking into account the overpressure produced by classical heating, the pressure charged on the FP was 2.2 bar of $\mathrm{H}_{2}$, which rose to 3.2 bar once the reaction was placed in the oil bath. This way the pressure conditions were equal between conventional and magnetically induced heating (3.2 bar during the reaction). Conventional heating worked positively in the case of BPE, for which after $5 \mathrm{~h}$ a $94 \%$ of the product was consumed compared to the $100 \%$ conversion obtained using the magnetic coil (see Table 6). However, in the case of DPE only an $18 \%$ conversion was obtained with conventional heating, compared to a $64 \%$ obtained by magnetic heating (see Table 5). As DPE possesses higher bond dissociation energy than BPE, its conversion in both instances is lower. The difference in reactivity between both species under conventional and magnetic heating points to a much higher temperature at the surface of the catalyst than that of the mean solution in the case of magnetic heating.

Finally, the recycling experiments seem contradictory since in some cases (furfural, cyclopentanone) little or no deactivation is observed. In these cases, the NPs mean size does not seem much affected by the magnetic heating although some agglomeration is observed. The decrease in the catalytic properties in the case of diphenyl ether can be due to two factors: i) the decrease of the catalytically active surface and ii) a decrease of the heating power of the particles. We have previously demonstrated the effect of the NPs organization into macroscopic needles on 
one side and of the formation of shapeless agglomerates on the other, which leads in the first case to a strong heating power and in the second one to virtually no heating. ${ }^{49}$ The higher solubility of the particles in mesitylene may allow them to move freely and organize in the magnetic field leading to an improved heating power (see the improvement of catalysis for furfural) while the particles in decane are less soluble and more agglomerated which could explain a reduced heating power. Nevertheless, we show here that recycling is possible and that magnetic heating does not lead to a rapid deactivation of the catalysts through coalescence of the NPs.

\section{Concluding remarks}

In summary, herein we report a new methodology for the valorization of biomass-derived molecules using magnetically induced catalysis and the easily accessible FeNi $3 @ N i$ NPs. Magnetic heating induces the performance of these difficult reactions thanks to the local heating of nanocatalysts above the boiling point of the solvent. This approach enables the cleavage of $\mathrm{C}-\mathrm{O}$ bonds of different functional groups such as ketones, aldehydes and aryl ethers, in spite of their high BDEs, and the reaction leads to high selectivity for the HDO products of furfural derivatives. The magnetic characteristics of the catalyst enables activation at lower magnetic field amplitudes than those reported previously, ${ }^{47}$ rendering the catalytic process more energetically efficient. Moreover, the high abundance and low cost of Fe and Ni make this catalyst promising for scale-up purposes.

The combination of magnetic heating which only requires a simple set-up and low pressures, and the catalytic properties of $\mathrm{FeNi}_{3} @ \mathrm{Ni} \mathrm{NPs}$ lead to catalytic performances so far typically obtained under harsher conditions or using noble metals. Magnetic heating of nano-catalysts in solution may therefore develop as a powerful and energy efficient new tool for the transformation of organic matter.

\section{Acknowledgements}

The authors thank ERC Advanced Grant (MONACAT 2015-694159) and IDEX/Chaires d'attractivité de l'Université Fédérale de Toulouse Midi-Pyrénées for financial support. 


\section{References}

1. Y. Jing, Y. Guo, Q. Xia, X. Liu and Y. Wang, Chem, 2019, 5, 2520-2546.

2. J.-Y. Kim, H. W. Lee, S. M. Lee, J. Jae and Y.-K. Park, Bioresource Technology, 2019, 279, $373-$ 384.

3. M. Besson, P. Gallezot and C. Pinel, Chemical Reviews, 2014, 114, 1827-1870.

4. S. Kim, E. E. Kwon, Y. T. Kim, S. Jung, H. J. Kim, G. W. Huber and J. Lee, Green Chemistry, 2019, 21, 3715-3743.

5. S. Chen, R. Wojcieszak, F. Dumeignil, E. Marceau and S. Royer, Chemical Reviews, 2018, 118, 11023-11117.

6. W. Jin, L. Pastor-Pérez, D. Shen, A. Sepúlveda-Escribano, S. Gu and T. Ramirez Reina, ChemCatChem, 2019, 11, 924-960.

7. C. Wang, H. Xu, R. Daniel, A. Ghafourian, J. M. Herreros, S. Shuai and X. Ma, Fuel, 2013, 103, 200-211.

8. S. Jężak, M. Dzida and M. Zorębski, Fuel, 2016, 184, 334-343.

9. D. A. Rothamer and J. H. Jennings, Fuel, 2012, 98, 203-212.

10. M. Thewes, M. Muether, S. Pischinger, M. Budde, A. Brunn, A. Sehr, P. Adomeit and J. Klankermayer, Energy \& Fuels, 2011, 25, 5549-5561.

11. P. Panagiotopoulou and D. G. Vlachos, Applied Catalysis A: General, 2014, 480, 17-24.

12. J. Zhang, L. Lin and S. Liu, Energy \& Fuels, 2012, 26, 4560-4567.

13. X. Chang, A.-F. Liu, B. Cai, J.-Y. Luo, H. Pan and Y.-B. Huang, ChemSusChem, 2016, 9, 33303337.

14. B. Saha, C. M. Bohn and M. M. Abu-Omar, ChemSusChem, 2014, 7, 3095-3101.

15. S. Srivastava, G. C. Jadeja and J. Parikh, RSC Advances, 2016, 6, 1649-1658.

16. S. Srivastava, G. C. Jadeja and J. Parikh, Journal of Molecular Catalysis A: Chemical, 2017, 426, 244-256.

17. X. Kong, Y. Zhu, H. Zheng, F. Dong, Y. Zhu and Y.-W. Li, RSC Advances, 2014, 4, 60467-60472.

18. B. Chen, F. Li, Z. Huang and G. Yuan, Applied Catalysis B: Environmental, 2017, 200, 192199.

19. S. Sitthisa, W. An and D. E. Resasco, Journal of Catalysis, 2011, 284, 90-101.

20. X. Liu, W. An, C. H. Turner and D. E. Resasco, Journal of Catalysis, 2018, 359, 272-286.

21. Q. Han, M. U. Rehman, J. Wang, A. Rykov, O. Y. Gutiérrez, Y. Zhao, S. Wang, X. Ma and J. A. Lercher, Applied Catalysis B: Environmental, 2019, 253, 348-358.

22. P. Jia, X. Lan, X. Li and T. Wang, ACS Sustainable Chemistry \& Engineering, 2019, 7, 1522115229.

23. W. Wang, N. Li, G. Li, S. Li, W. Wang, A. Wang, Y. Cong, X. Wang and T. Zhang, ACS Sustainable Chemistry \& Engineering, 2017, 5, 1812-1817.

24. J. Yang, N. Li, G. Li, W. Wang, A. Wang, X. Wang, Y. Cong and T. Zhang, Chemical Communications, 2014, 50, 2572.

25. M. Hronec, K. Fulajtárova, T. Liptaj, M. Štolcová, N. Prónayová and T. Soták, Biomass and Bioenergy, 2014, 63, 291-299.

26. P. Azadi, O. R. Inderwildi, R. Farnood and D. A. King, Renewable and Sustainable Energy Reviews, 2013, 21, 506-523.

27. J. Ralph, C. Lapierre and W. Boerjan, Current Opinion in Biotechnology, 2019, 56, 240-249.

28. M. Zaheer and R. Kempe, ACS Catalysis, 2015, 5, 1675-1684.

29. Y.-R. Luo, Comprehensive Handbook of Chemical Bond Energies, CRC Press, Boca Raton, 2007.

30. J. He, C. Zhao and J. A. Lercher, Journal of the American Chemical Society, 2012, 134, 2076820775.

31. A. G. Sergeev, J. D. Webb and J. F. Hartwig, Journal of the American Chemical Society, 2012, 134, 20226-20229.

32. E. C. Abenojar, S. Wickramasinghe, J. Bas-Concepcion and A. C. S. Samia, Progress in Natural Science: Materials International, 2016, 26, 440-448.

33. V. Iablokov, Y. Xiang, A. Meffre, P.-F. Fazzini, B. Chaudret and N. Kruse, ACS Catalysis, 2016, 6, 2496-2500.

34. A. Meffre, B. Mehdaoui, V. Connord, J. Carrey, P. F. Fazzini, S. Lachaize, M. Respaud and B. Chaudret, Nano Letters, 2015, 15, 3241-3248.

35. A. Bordet, L.-M. Lacroix, P.-F. Fazzini, J. Carrey, K. Soulantica and B. Chaudret, Angewandte Chemie International Edition, 2016, 55, 15894-15898. 
36. A. Bordet, J. M. Asensio, K. Soulantica and B. Chaudret, ChemCatChem, 2018, 10, 4047-4051.

37. S. S. Kale, J. M. Asensio, M. Estrader, M. Werner, A. Bordet, D. Yi, J. Marbaix, P.-F. Fazzini, K. Soulantica and B. Chaudret, Catalysis Science \& Technology, 2019, 9, 2601-2607.

38. W. Wang, G. Tuci, C. Duong-Viet, Y. Liu, A. Rossin, L. Luconi, J.-M. Nhut, L. Nguyen-Dinh, C. Pham-Huu and G. Giambastiani, ACS Catalysis, 2019, 9, 7921-7935.

39. W. Wang, C. Duong-Viet, Z. Xu, H. Ba, G. Tuci, G. Giambastiani, Y. Liu, T. Truong-Huu, J.-M. Nhut and C. Pham-Huu, Catalysis Today, 2019.

40. F. Varsano, M. Bellusci, A. La Barbera, M. Petrecca, M. Albino and C. Sangregorio, International Journal of Hydrogen Energy, 2019, 44, 21037-21044.

41. P. M. Mortensen, J. S. Engbæk, S. B. Vendelbo, M. F. Hansen and M. Østberg, Industrial \& Engineering Chemistry Research, 2017, 56, 14006-14013.

42. M. G. Vinum, M. R. Almind, J. S. Engbæk, S. B. Vendelbo, M. F. Hansen, C. Frandsen, J. Bendix and P. M. Mortensen, Angewandte Chemie International Edition, 2018, 57, 10569-10573.

43. J. Marbaix, N. Mille, L.-M. Lacroix, J. M. Asensio, P.-F. Fazzini, K. Soulantica, J. Carrey and B. Chaudret, ACS Applied Nano Materials, 2020, 3, 3767-3778.

44. S. Ceylan, C. Friese, C. Lammel, K. Mazac and A. Kirschning, Angewandte Chemie International Edition, 2008, 47, 8950-8953.

45. Y. Liu, P. Gao, N. Cherkasov and E. V. Rebrov, RSC Advances, 2016, 6, 100997-101007.

46. S. Gyergyek, A. Kocjan, M. Grilc, B. Likozar, B. Hočevar and D. Makovec, Green Chemistry, 2020, 22, 5978-5983.

47. J. M. Asensio, A. B. Miguel, P.-F. Fazzini, P. W. N. M. van Leeuwen and B. Chaudret, Angewandte Chemie International Edition, 2019, 58, 11306-11310.

48. D. De Masi, J. M. Asensio, P. F. Fazzini, L. M. Lacroix and B. Chaudret, Angewandte Chemie International Edition, 2020, 59, 6187-6191.

49. J. M. Asensio, J. Marbaix, N. Mille, L.-M. Lacroix, K. Soulantica, P.-F. Fazzini, J. Carrey and B. Chaudret, Nanoscale, 2019, 11, 5402-5411.

50. B. Mehdaoui, R. P. Tan, A. Meffre, J. Carrey, S. Lachaize, B. Chaudret and M. Respaud, Physical Review B, 2013, 87, 174419.

51. J. He, C. Zhao, D. Mei and J. A. Lercher, Journal of Catalysis, 2014, 309, 280-290.

52. P. Yang, Q. Cui, Y. Zu, X. Liu, G. Lu and Y. Wang, Catalysis Communications, 2015, 66, 55-59.

53. P. Yang, Q. Xia, X. Liu and Y. Wang, Journal of Energy Chemistry, 2016, 25, 1015-1020.

54. D. P. Duarte, R. Martínez and L. J. Hoyos, Industrial \& Engineering Chemistry Research, 2015, 55, 54-63. 